\title{
Evolution of venous thromboembolism risk assessment in trauma and surgical patients
}

\author{
Krishna Akella \\ Akella Chendrasekhar \\ Department of Surgery, Richmond \\ University Medical Center, Staten \\ Island, NY, USA
}

This article was published in the following Dove Press journal:

Open Access Surgery

26 October 2016

Number of times this article has been viewed

Introduction: Development of venous thromboembolism (VTE) is a common cause of inhospital morbidity and mortality. The initial evaluation of VTE risk in hospitalized surgical patients has become the standard of care. In an attempt to ascertain why patients who had received adequate prophylaxis on initial evaluation had subsequently developed VTE, we hypothesized that in the absence of changing levels of care, risk of VTE does increase in the hospitalized surgical patient population. As the treatment paradigms for moderate and high risk patients are equivalent, we also hypothesized that this change resulted in under-treatment with regard to prophylaxis of VTE.

Patients and methods: A retrospective data analysis was performed on 96 adult patients admitted to our surgical service. The initial VTE risk assessment and prophylactic guidelines are based on set criteria mandated by our institution. The initial VTE risk and prophylaxis on admission was noted for each patient. The patient was then subsequently re-evaluated during the hospitalization using the same criteria. Additional information obtained included demographic data, prior surgery, hospital-length of stay, prior history of DVT, and whether or not prophylaxis was appropriate initially and on reassessment. A one-way analysis of variance was then performed.

Results: Among the 96 enrolled patients, 76 progressed in their VTE risk resulting in change of risk category. Change by one category of risk occurred in 33 patients, two categories occurred in 19 patients, and three categories occurred in 24 patients. In addition to change in risk category, the need for change in prophylaxis was also evaluated in these patients by comparing percentage of patients given appropriate prophylaxis initially and again on re-evaluation.

Discussion: We feel that repeated reassessment of VTE risk throughout a hospital stay is indicated. Prophylactic measures based on risk should also be adjusted accordingly.

Keywords: venous thromboembolism, risk assessment, re-evaluation.

\section{Introduction}

Development of venous thromboembolism (VTE) is a common cause of in-hospital morbidity and mortality. VTE is a term that encompasses the continuum of deep vein thrombosis (DVT) and pulmonary embolism (PE). Annual incidence of VTE is estimated to be $300,000-600,000$ cases in the US. ${ }^{1-3}$ Due to difficulty in documenting DVT and $\mathrm{PE}$, limitations in databases, and specificity of community-based studies, this condition is seriously under-reported. ${ }^{4,5}$ The initial evaluation of VTE risk in hospitalized surgical patients has become the standard of care in an attempt to address this issue. It is not uncommon for a hospitalized patient to develop hypercoagulability, particularly in the postoperative setting, due to a number of factors. The inflammatory response
Correspondence: Akella Chendrasekhar Department of Surgery, Richmond University Medical Center, 355 Bard Avenue, Staten Island, NY 10310 , USA Tel +17188182421

Email Chendrasekharakella@gmail.com 
essential for wound healing is also causative in offsetting the balance of pro- and anti-thrombotic factors necessary for proper hemostasis. ${ }^{6}$ In an attempt to ascertain why patients who had received adequate prophylaxis on initial evaluation had subsequently developed VTE, we hypothesized that in the absence of changing levels of care, risk of VTE does increase in the hospitalized surgical patient population. As the treatment paradigms for moderate and high risk patients are equivalent, we also hypothesized that this change resulted in under-treatment with regard to prophylaxis of VTE.

\section{Materials and methods}

A retrospective data analysis was performed on 96 adult patients admitted to our surgical service. The initial VTE risk assessment and prophylactic guidelines are based on set criteria, modified from the Wells DVT Scoring Criteria, ${ }^{7}$ mandated by our institution. As our study pertained to evaluation of VTE risk development, patients with current or prior VTE were excluded from the analysis. This study was deemed exempt from full review according to the Institutional Review Board of SUNY Downstate Medical Center as this was a retrospective data analysis using de identified patient data. Because of this the Institutional Review Board of SUNY Downstate Medical Center also deemed patient consent unnecessary. The initial VTE risk and prophylaxis on admission was noted for each patient. The patient was then subsequently re-evaluated during the hospitalization using the same criteria. In addition to performing a chart review, each patient was evaluated at the bedside to assess for clinical status that could alter VTE risk as part of a performance improvement protocol. Our VTE assessment used a point-based system for evaluation shown in Table 1. An individual's risk is based on the cumulative points given by the presence of particular risk factors. These cumulative points then place the patient into a particular category of VTE risk, which determines the degree of prophylaxis: $0-1$ points $=$ low risk, 2 points $=$ moderate risk, 3-4 points $=$ high risk, $5+=$ very high risk. Prophylactic measures are illustrated in Table 2. Additional information obtained included demographic data, prior surgery, hospital-length of stay, prior history of DVT, and whether or not prophylaxis was appropriate initially and on reassessment. A one-way analysis of variance was then performed using JMP Statistical Software ${ }^{\odot}$ (SAS Institute Inc., Cary, NC, USA).

\section{Results}

Of the 99 patients originally screened, three patients were excluded due to the presence of VTE. The remaining 96 patients consisted of 53 males and 43 females, with a mean age of 60 years. Initial risk scores ranged from 0-7. Upon re-evaluation, scores ranged from 1-20. Re-evaluation occurred within the hospitalization period ranging from 1-78 days post-admission. Among the 96 enrolled patients, 76 progressed in their VTE risk resulting in change of risk category. Change by one category of risk occurred in 33 patients, two categories occurred in 19 patients, and three categories occurred in 24 patients (Figure 1). In addition to

Table I VTE risk factors and corresponding point appropriations

\begin{tabular}{|c|c|c|c|}
\hline One point & Two points & Three points & Five points \\
\hline I. Age $4 I-60$ years & I. Age $60-74$ years & I. Age 75 years and above & I. Elective arthroplasty \\
\hline 2. Minor elective surgery & 2. Malignancy & 2. Family history of VTE & 2. Pelvic or leg fracture \\
\hline 3. Lower extremity edema & 3. Arthroscopic surgery in & 3. Factor V Leiden & 3. Stroke \\
\hline 4. Varicose veins & the last month & 4. Lupus anticoagulant & 4. Multiple trauma \\
\hline $\begin{array}{l}\text { 5. Major surgery (over } 45 \text { mins) in the last } \\
\text { month prior }\end{array}$ & $\begin{array}{l}\text { 4. Major surgery in the last } \\
\text { month }\end{array}$ & $\begin{array}{l}\text { 5. Anti-cardiolipin antibodies } \\
\text { 6. HIT }\end{array}$ & $\begin{array}{l}\text { 5. Acute spinal cord injury or } \\
\text { paralysis in the last month }\end{array}$ \\
\hline 6. Adnormal PFT & 5. Immobilized with plaster & 7. Other thrombophilia & \\
\hline 7. Obesity & caste in the last month & & \\
\hline 8. COPD & 6. Central venous access & & \\
\hline \multicolumn{4}{|l|}{ 9. Inflammatory bowel disease } \\
\hline \multicolumn{4}{|l|}{ 10. $\mathrm{AMI}$ or $\mathrm{CHF}$} \\
\hline \multicolumn{4}{|l|}{ II. Sepsis } \\
\hline \multicolumn{4}{|l|}{ 12. Serious lung disease } \\
\hline \multicolumn{4}{|l|}{ (eg, pneumonia) in the last month } \\
\hline \multicolumn{4}{|l|}{ 13. Bed rest } \\
\hline \multicolumn{4}{|l|}{ 14. OCP or HRT } \\
\hline \multicolumn{4}{|l|}{ 15. Pregnancy or I month post-partum } \\
\hline \multicolumn{4}{|l|}{ 16. Females with unexplained stillbirths, three } \\
\hline or more recurrent spontaneous abortions, & & & \\
\hline premature birth with toxemia or growth & & & \\
\hline restricted infants & & & \\
\hline
\end{tabular}

Abbreviations: AMI, acute myocardial infarction; CHF, congestive heart failure; COPD, chronic obstructive pulmonary disease; HIT, heparin induced thrombocytopenia; HRT, hormone replacement therapy; OCP, oral contraceptive pills; PFT, pulmonary function tests; VTE, venous thromboembolism. 
Table 2 Prophylactic measures of VTE risk categories

\begin{tabular}{llll}
\hline Low risk (0-I Points) & Moderate risk (2 Points) & High risk (3-4 Points) & Very high risk (5 or more Points) \\
\hline I. Early ambulation & I. Early ambulation & I. Early ambulation & I. Early ambulation \\
$\begin{array}{ll}\text { 2. Intraoperative pneumatic } \\
\text { compression }\end{array}$ & $\begin{array}{l}\text { 2. Intraoperative pneumatic } \\
\text { compression }\end{array}$ & $\begin{array}{l}\text { 2. Intraoperative pneumatic } \\
\text { compression }\end{array}$ & $\begin{array}{l}\text { 2. Intraoperative pneumatic compression } \\
\end{array}$ \\
$\begin{array}{llll}\text { 3. Enoxaparin or low-dose } \\
\text { unfractionated heparin }\end{array}$ & $\begin{array}{l}\text { 3. Enoxaparin or low-dose } \\
\text { unfractionated heparin }\end{array}$ & $\begin{array}{l}\text { 3. Enoxaparin, warfarin, or intermittent } \\
\text { pneumatic compression with } \\
\text { unfractionated or LMW heparin }\end{array}$ \\
\hline
\end{tabular}

Abbreviations: LMW, low molecular weight; VTE, venous thromboembolism.

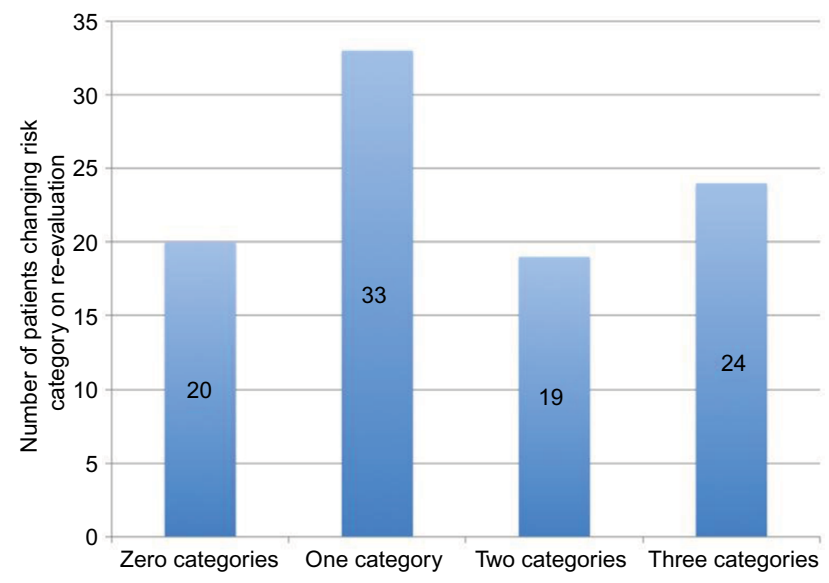

Figure I Number of patients changing risk category on re-evaluation vs number of VTE risk categories changed.

Abbreviation: VTE, venous thromboembolism.

Table 3 Percentage of patients receiving appropriate VTE prophylaxis vs VTE risk category

\begin{tabular}{lll}
\hline & \multicolumn{2}{l}{ Percentage of appropriate prophylaxis } \\
\hline Risk category & Initial evaluation & Re-evaluation \\
\hline Low risk & 100 & 100 \\
Moderate risk & $87 \pm 7.1$ & $60 \pm 16.3$ \\
High risk & $95 \pm 4.3$ & $80 \pm 13.3$ \\
Very high risk & $21 \pm 11.3$ & $6.8 \pm 2.9$ \\
\hline
\end{tabular}

Note: Data shown as $\% \pm$ SD

Abbreviation: VTE, venous thromboembolism.

the change in risk category, the need for change in prophylaxis was also evaluated in these patients by comparing the percentage of patients given appropriate prophylaxis initially and again on re-evaluation. Most notably, an appropriate level of prophylaxis was achieved $21 \%$ of the time initially in the very high risk group-dropping to $6.8 \%$ on re-evaluation. A similar trend was noted in the high risk group (from 95\% initially to $80 \%$ on re-evaluation) and the moderate risk group (from $87 \%$ initially to $60 \%$ on re-evaluation). The low risk group had achieved appropriate levels of prophylaxis $100 \%$ of the time initially and on re-evaluation (Table 3 ).

\section{Discussion}

VTE is defined by presence of PE and/or DVT and is the leading cause of preventable hospital mortality in the US. The primary cause of mortality in VTE is due to PE, accounting for one third of VTE cases, commonly resulting in sudden death. ${ }^{89}$ While at least $50 \%$ of patients with VTE will have risk factors, occurrence is commonly idiopathic. ${ }^{10,11}$

Major predisposing factors are characterized by Virchow's Triad-venous stasis, hypercoagulability, and intimal damage. Lower extremity DVT most commonly develops from deep leg veins. ${ }^{12}$ The formed thrombus then begins to progress proximally resulting in symptoms of pain, edema, tenderness, and erythema. ${ }^{13-15}$ This condition can progress to development of emboli, resulting in dyspnea and chest pain associated with PE. As a thrombus ages beyond 5-10 days, fibrin polymerization and cross-linking decreases probability of embolization. ${ }^{16}$

As this condition can commonly be idiopathic, it is important to have a high index of suspicion, particularly in the postoperative patient. Trauma and major surgery classically include multiple risk factors for development of DVT-collectively responsible for $40 \%$ of VTE. Rate of postoperative DVT in non-anticoagulated patients is $70 \%$ for nonelective hip surgery, $48 \%$ for elective orthopedic surgery, and $12 \%$ for elective general surgery. Of these postoperative DVT, $20 \%$ develop into PE with a $30 \%$ mortality rate. Despite prophylaxis, 5-10\% of orthopedic patients develop PE postoperatively. ${ }^{11,17}$

Duplex ultrasound is the most common test ordered for DVT, evaluating for vein collapsibility, blood color on spectral doppler, and blood flow. Although this modality is user dependent, accuracy is reported up to $98 \%{ }^{18}$ Initial interventional therapy entails use of anticoagulation with heparin.

A patient's post-hospitalization VTE risk has traditionally been assumed to be static. The aim of our study was twofold. First was to ascertain whether or not a static VTE risk was a reasonable assumption to make over a patient's hospitalization course. Second was to evaluate if this change in VTE risk also resulted in the need for more aggressive prophylaxis. The data in our study suggest that rather than being static, a patient's VTE risk is a dynamic process. As this risk continues to evolve, so does the need for more aggressive prophylactic measures. As moderate and high risk 
categories have the same prophylactic measures, changes in these measures were most important when moving from low to moderate/high risk and from moderate/high risk to very high risk. The change in an appropriate level of prophylaxis achieved in the very high risk category (initially $21 \%$ and $6.8 \%$ on re-evaluation) is evidence in support of this-as patients changed their VTE risk category, the initial measures for prophylaxis were no longer appropriate. One of the major limitations of our study was the significant range of time for re-evaluation. As this was variable with a wide range, this may have been a confounding factor. This issue was unavoidable as the chart review took place on patients with a varying length of stay. Our paper is the first to show a change in risk category for patients being provided the same level of care during their hospitalization. In conclusion, we feel that repeated reassessment of VTE risk throughout a hospital stay is indicated. Prophylactic measures based on risk should also be adjusted accordingly.

\section{Disclosure}

The authors report no conflicts of interest in this work.

\section{References}

1. Silverstein MD, Heit JA, Mohr DN, Petterson TM, O'Fallon WM, Melton LJ 3rd. Trends in the incidence of deep vein thrombosis and pulmonary embolism: a 25-year population-based study. Arch Intern Med. 1998;158(6):585-593.

2. Spencer FA, Emery C, Lessard D, et al. The Worcester Venous Thromboembolism study: a population-based study of the clinical epidemiology of venous thromboembolism. J Gen Intern Med. 2006;21(7):722-727.

3. White RH, Zhou H, Murin S, Harvey D. Effect of ethnicity and gender on the incidence of venous thromboembolism in a diverse population in California in 1996. Thromb Haemost. 2005;93(2):298-305.

4. U.S. Department of Health \& Human Services. The Surgeon General's Call to Action to Prevent Deep Vein Thrombosis and Pulmonary Embolism. Rockville, MD, USA. Available from: www.surgeongeneral.gov/ topics/deepvein/calltoaction/call-to-action-on-dvt-2008.pdf. Accessed January 15, 2016
5. Raskob GE, Silverstein R, Bratzler DW, Heit JA, White RH. Surveillance for deep vein thrombosis and pulmonary embolism: recommendations from a national workshop. Am J Prev Med. 2010;38(4 Suppl): S502-S509.

6. Corbett SA. Systemic Response to Injury and Metabolic Support. In: Brunicardi F, Andersen DK, Billiar TR, Dunn DL, Hunter JG, Matthews JB, Pollock RE. editors. Schwartz's Principles of Surgery, 10th edition. New York, NY: McGraw-Hill; 2014. Available from: http://accesssurgery.mhmedical.com.dmu.idm.oclc.org/content.aspx?bookid=980\&S ectionid=59610843. Accessed February 06, 2016.

7. Geersing GJ, Zuithoff NPA, Kearon C, et al. Exclusion of deep vein thrombosis using the Wells rule in clinically important subgroups: individual patient data meta-analysis. BMJ. 2016;348(2014):g1340.

8. Maynard G, Stein J. Preventing hospital-acquired venous thromboembolism: a guide for effective quality improvement. Rockville MD: Agency for Healthcare Research and Quality, August 2008. AHRQ Publication No. 08-0075. Available from: www.ahrq.gov/qual/vtguide/. Accessed January 15,2016

9. Chang J, Elam-Evans LD, Berg CJ, et al. Pregnancy-related mortality surveillance --United States, 1991-1999. MMWR CDC Surveill Summ. 2003;52(2):1-8.

10. Cogo A, Bernardi E, Prandoni P, Girolami B, Noventa F, Simioni P, Girolami A. Acquired risk factors for deep-vein thrombosis in symptomatic outpatients. Arch Intern Med. 1994;151(2):164-168.

11. Goldhaber SZ, Tapson VF; DVT FREE Steering Committee. A prospective registry of 5,451 patients with ultrasound- confirmed deep vein thrombosis. Am J Cardiol 2004;93(2):259-262.

12. Cogo A, Lensing AW, Prandoni P, et al. Distribution of thrombosis in patients with symptomatic deep vein thrombosis. Implications for simplifying the diagnostic process with compression ultrasound. Arch Intern Med. 1993;153(24):2777-2780.

13. Kazmers A, Groehn H, Meeker C. Do patients with acute deep vein thrombosis have fever? Am Surg. 2000;66(6):598-601.

14. Aburahma AF, Saiedy S. Deep vein thrombosis as probable cause of fever of unknown origin. WV Med J. 1997;93(1):368-370.

15. Stein PD, Afzal A, Henry JW, Villareal CG. Fever in acute pulmonary embolism. Chest. 2000;117(1):39-42.

16. Browse NL, Burnand KG, Irvine AT, Wilson NM. Deep vein thrombosis: Pathology. In: Browse NL, Burnand KG, Irvine AT, Wilson NM, editorss. Diseases of the Veins. 2nd ed. London, England: Arnold Publishers; 1999:249-289.

17. Feied C. Deep Venous Thrombosis. eMedicine.com. 2005. Available at: $\mathrm{http}: / /$ www.emedicine.com/med/topic2785.htm. Accessed February 06, 2016.

18. Kearon C, Julian JA, Newman TE, Ginsberg JS. Noninvasive diagnosis of deep venous thrombosis. McMaster Diagnostic Imaging Practice Guidelines Initiative. Ann Intern Med. 1998;128(8):663-677.
Open Access Surgery

\section{Publish your work in this journal}

Open Access Surgery is an international, peer-reviewed, open access journal that focuses on all aspects of surgical procedures and interventions. Patient care around the peri-operative period and patient outcomes post surgery are key topics for the journal. All grades of surgery from minor cosmetic interventions to major surgical procedures are covered. Novel techniques and the

\section{Dovepress}

utilization of new instruments and materials, including implants and prostheses that optimize outcomes constitute major areas of interest. The manuscript management system is completely online and includes a very quick and fair peer-review system, which is all easy to use. Visit http://www.dovepress.com/ testimonials.php to read real quotes from published authors. 